\title{
On the influence of nucleation on the toughness of iPP/EPR blends with different rubber molecular architectures
}

\author{
C. Grein*, M. Gahleitner \\ Borealis Polyolefine GmbH, St. Peter Strasse 25, A-4021 Linz, Austria
}

Received 26 February 2008; accepted in revised form 6 April 2008

\begin{abstract}
The influence of $\alpha$ - and $\beta$-nucleating agents on the fracture performance of two different 32 wt $\%$ rubber modified isotactic Polypropylene (iPP) reactor blends is discussed as a function of the phase morphology of the investigated systems. Nucleation for systems with a large inter-particle distance was found to have only a limited impact on the temperature at which the ductile-brittle transition occurs, negative for $\alpha$-nucleated blends, almost negligible for $\beta$-nucleated resins. For blends exhibiting a small inter-particular distance between their ethylene-propylene rubber (EPR) phase, toughness was promoted slightly by $\alpha$-nucleation and to a large extent by $\beta$-nucleation as compared to a non-nucleated reference. These findings raise the importance of mechanistic synergies between the rubbery phase and the matrix to maximize the fracture resistance of blends.
\end{abstract}

Keywords: polymer blends and alloys, PP/EPR blends, fracture, damage mechanism, nucleation

\section{Introduction}

Mechanical properties of semi-crystalline polymers like polypropylene (PP) are mostly determined by their crystalline structure and consequently massively affected by nucleation. For single-phase systems, mostly for isotactic PP homopolymers (iPP), the effect of selective nucleation both of the $\alpha$ phase $[1,2]$ and of the $\beta$-phase $[3,4]$ has been studied extensively already. The molecular weight of the respective polymers was found to be the dominating factor for mechanical consequences of nucleation in this case and is valid for a wide range of processing modes from injection molded specimens to vibration welded parts [5].

The respective influence of nucleating agents ( $\alpha$ or $\beta$ ) on the mechanical performances of heterophasic systems composed of an iPP matrix and an ethylene-propylene rubber (EPR) is still controversial, consequence of a lack of published experimental data. Whereas several studies have reported posi- tive effects of nucleation on the fracture resistance of iPP/EPR blends [6-12], other contributions showed limited (for $\beta$-nucleation) [4, 13-16] or even negative (for $\alpha$-nucleating agents) ones [4, 17, 18]. The goal of the present investigation was to identify potential coupling effect between the matrix crystalline structure induced by nucleation and the morphology of the rubbery phase in order to clarify this apparent contradiction. Two iPP/EPR reactor blends containing about $32 \mathrm{wt} \%$ of dispersed rubber phase were investigated. Their phase morphology was controlled by varying the molecular weight of the in-reactor made elastomer (EPR). One material contained a rubber with low molecular weight, expressed by an intrinsic viscosity (IV) of $1.9 \mathrm{dl} / \mathrm{g}$, the other one had an IV of $4.2 \mathrm{dl} / \mathrm{g}$. The focus was set on the determination of ductile-brittle transitions since standard characterisation methods were found to be insufficient to discriminate the studied grades sufficiently. 


\section{Experimental}

\subsection{Materials}

Two reactor-made iPP/EPR blends produced with a high yield $4^{\text {th }}$ generation Ziegler-Natta-catalyst in a pilot facility from Borealis using multiple reactors were studied. Both grades contained $32 \mathrm{wt} \%$ of xylene cold soluble (XCS, approximated to be the EPR content), had a propylene-rich rubber (C3XCS of about $55 \mathrm{wt} \%$ ) and exhibited a matrix MFR of about $60 \mathrm{~g} / 10 \mathrm{~min}$. The rubbery phase of material 1, PP-1.9, had an intrinsic viscosity (IV) of $1.9 \mathrm{dl} / \mathrm{g}$, the dispersed phase of its counterpart, PP4.2 , an IV of $4.2 \mathrm{dl} / \mathrm{g}$.

The materials were nucleated with $0.1 \%$ of NA11 (Sodium 2,2'-methylene bis-(4,6-di-tert. butylphenyl) phosphate) as $\alpha$-nucleating agent manufactured by Asahi Denka (resp. distributed by Adeka Palmarole) and $0.1 \%$ of proprietary calcium pimelate (CaPim) as $\beta$-nucleating agent [19]. Nonnucleated references were also studied. Compounds were made on a TSE24 twin-screw extruder and stabilised with a conventional additive package. The efficiency of the nucleation effect was controlled by DSC (Differential Scanning Calorimetry) using the information of the first cooling and second heating scan of a $10 /-10 / 10^{\circ} \mathrm{C} / \mathrm{min}$ scanning program between 23 and $210^{\circ} \mathrm{C}$. Both $\alpha$-nucleated iPP/EPR blends had thus a crystallisation temperature around $130^{\circ} \mathrm{C}$ accounting for fully $\alpha$-nucleated systems; both $\beta$-nucleated grades exhibited a crystallisation temperature of about $124^{\circ} \mathrm{C}$ and a $\beta$-phase as from DSC of more than $80 \%$ Although we are aware that this DSC-method is not the best one to determine the $\beta$-content of iPP blends $[20,21]$, our experience suggests that the investigated samples are almost completely $\beta$-nucleated.

\subsection{Experimental techniques}

The melt flow rate (MFR) of the investigated grades was measured in accordance to ISO 1133 at a load of $2.16 \mathrm{~kg}$ using a temperature of $230^{\circ} \mathrm{C}$. Xylene cold soluble (XCS) content was determined according to ISO 6427. The $\mathrm{C} 3$ content of the dispersed phase, C3(XCS), was measured according to EN 17025 with FTIR (Fourier Transformations Infrared Spectroscopy) calibrated with ${ }^{13} \mathrm{C}-\mathrm{NMR}$ (Nuclear Magnetic Resonance). The intrinsic vis- cosity (IV) of XCS fraction was assessed by ISO 1628 in decahydronaphthalin at $135^{\circ} \mathrm{C}$.

For an overall thermomechanical profile, dynamic mechanical analysis (DMTA) was performed in accordance with ISO 6721 with $50 \times 10 \times 1 \mathrm{~mm}^{3}$ compression moulded samples, as a function of temperature at $1 \mathrm{~Hz}$ with a heating rate of $2 \mathrm{~K} / \mathrm{min}$ under forced oscillation in a torsion mode $(\varepsilon=$ $0.04 \%$ ) with an RDS II (Rheometrics).

Charpy notched impact strengths (NIS) were measured at 23 and $-20^{\circ} \mathrm{C}$ according to ISO $179 / 1 \mathrm{eA}$ (test speed of about $3 \mathrm{~m} / \mathrm{s}$ ), flexural elastic moduli were recorded at $23^{\circ} \mathrm{C}$ according to ISO 178 on $80 \times 10 \times 4 \mathrm{~mm}^{3}$ specimens at a test speed of $50 \mathrm{~mm} / \mathrm{min}$. All the materials were injection moulded under the same standard conditions in line with EN ISO 1873-2. The parts were not conditioned prior to testing, which was done at least $96 \mathrm{~h}$ after moulding.

Ductile-brittle transitions were determined on a Charpy Instrumented Pendulum. The energy of the pendulum was fixed and valued $50 \mathrm{~J}$. For data acquisition and data reduction software developed by Borealis was applied. Force-displacement curves were recorded and analysed.

The work to break, $G_{t o t}$, was calculated from Equation (1):

$$
G_{t o t}=\frac{U_{t o t}}{B(W-a)}
$$

where $U_{\text {tot }}$ is the energy to break of the SENB (Single Edge Notched Bending) specimen, $B$ is the thickness of the sample, $W$ is the width of the sample, $a$ is the crack length of the sample.

While the test speed was maintained constant $(1.5 \mathrm{~m} / \mathrm{s})$, the temperature $T$ was varied in between -60 and $100^{\circ} \mathrm{C}$, in steps of $10 \mathrm{~K}$ far from the ductile-brittle transition and steps of $2^{\circ} \mathrm{C}$ near to it. The transitions were taken to be the inflexion points in the curves $G_{t o t}=f(T)$. In this case, the lower the temperature at which the ductile-brittle transition $\left(T_{d b}\right)$ occurred, the tougher is the material.

Note moreover that the indicated $G_{t o t}$ values in the ductile range have to be considered with caution. Since the samples didn't break, only the broken sample width $\left(W_{\text {broken }}\right)$ involved in the fracture process $\left(W_{\text {broken }}<W\right)$ should have been taken into account in the calculations. The $G_{t o t}$ are thus underestimated all the more as the test temperature 
increased ( $W_{\text {broken }}$ decreasing with increasing this latter).

Transmission electron micrographs of PP-1.9 and PP-4.2 were performed on $100 \mathrm{~nm}$ ultrathin cuts after staining the specimen with ruthenium tetroxide [22]. The specimens were prepared from the core section of the injection moulded bars.

\section{Results and discussion}

The dynamic mechanical response of the different systems with an IV of $4.2 \mathrm{dl} / \mathrm{g}$ is given in Figure 1; the trends observed are the same for the PP-1.9 blends. While the peak of the rubbery phase is independent of the nucleation, appearing at about $-50^{\circ} \mathrm{C}$, the glass transition temperature of the iPP matrix is affected to a non negligible extent by the nucleation modified crystalline phase.

Hence, the $T_{g}$ of the neat system is around $0^{\circ} \mathrm{C}$, the $T_{g}$ of the $\alpha$-nucleated blend is around $4^{\circ} \mathrm{C}$ and that of the $\beta$-nucleated Impact PP at about $8^{\circ} \mathrm{C}$. For this latter, one may notice the specific shape of this relaxation with its sharp coupling with the $T_{\alpha c}$ relaxation at $50^{\circ} \mathrm{C}$ - which has often been ascribe to promote toughness [23]. For the $\alpha$-nucleated blend, an increase of $4^{\circ} \mathrm{C}$ in the $T_{g}$ - at otherwise similar shape - compared to the neat system is expected to lead to more embrittlment, an expecta-

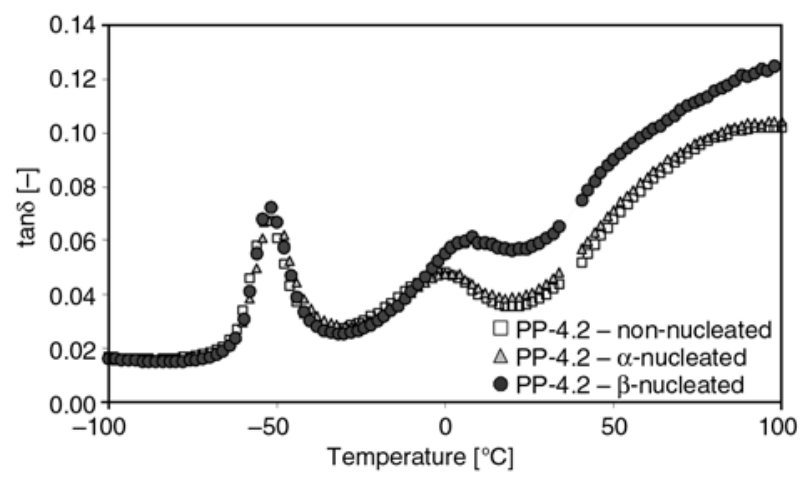

Figure 1. DMTA curves of non-nucleated, $\alpha$-nucleated and $\beta$-nucleated PP-4.2 tion which does not hold for all the grades studied as will be shown later on.

The particle size of the investigated blends - as highlighted in Figure 2 - is dependent of the intrinsic viscosity of their elastomer phase. As expected PP-1.9 exhibited smaller EPR inclusions than its homologue which had an IV of 4.2. As a consequence, the inter-particle distance (ID) of PP-1.9 was smaller to than that of PP-4.2. An estimation of $I D$ - assuming the rubber particles to be arranged in a cubic lattice - can be obtained using Equation (2) [24]:

$I D=d\left[\left(\frac{\pi}{6 \Phi}\right)^{\frac{1}{3}}-1\right]$

where $d$ is the average particle diameter and $\Phi$ is the rubber volume fraction.

Given that PP-1.9 has roughly an inclusion diameter of $400 \mathrm{~nm}$ and PP-4.2 roughly one of $1600 \mathrm{~nm}$ one obtains $I D(\mathrm{PP}-1.9) \sim 290 \mathrm{~nm}$ and $I D(\mathrm{PP}-4.2) \sim$ $1150 \mathrm{~nm}$, matrix ligaments in between particles are thus approximately 4 times larger in PP-4.2 than in PP-1.9. These calculations have been made for non-nucleated systems. Assumed in the following is that the phase morphology and thus the interparticular distance will not be affected by a nucleation using NA11 or calcium pimelate.

The melt flow rates (MFR), notched impact strengths (NIS) at 23 and $-20^{\circ} \mathrm{C}$ and the $E$-moduli at $23^{\circ} \mathrm{C}$ are given in Table 1 . While the stiffness values prove - in addition to the DSC results - that both nucleation modes were effective, the fracture resistance values are more tricky to interpret because those recorded at $23^{\circ} \mathrm{C}$ always account for a ductile mode of failure, while those carried out at $-20^{\circ} \mathrm{C}$ stand for a brittle failure mode. The NIS results tend to suggest that the low IV grades show disadvantages in the toughness compared to their higher IV homologues at room temperature as well

Table 1. Melt flow rates (MFR), notched impact strengths (NIS) at 23 and $-20^{\circ} \mathrm{C}$ and $E$-moduli at $23^{\circ} \mathrm{C}$ of $\mathrm{PP}-1.9$ and PP-4.2 (non-nucleated, $\alpha$-nucleated, $\beta$-nucleated)

\begin{tabular}{|l|c|c|c|c|}
\hline & MFR [g/10 $\mathbf{~ m i n}]$ & $\mathbf{N I S}\left(\mathbf{2 3}^{\circ} \mathbf{C}\right)\left[\mathbf{k J} / \mathbf{m}^{2}\right]$ & $\mathbf{N I S}\left(-\mathbf{2 0}{ }^{\circ} \mathbf{C}\right)\left[\mathbf{k J} / \mathbf{m}^{\mathbf{2}}\right]$ & $\mathbf{E}_{\text {flex }}[\mathbf{M P a}]$ \\
\hline PP-1.9 & 21.2 & $26.3 \pm 3.1$ & $5.3 \pm 0.3$ & $742 \pm 10$ \\
\hline PP-1.9+0.1\% NA11 & 21.2 & $33.0 \pm 0.9$ & $6.3 \pm 0.3$ & $940 \pm 11$ \\
\hline PP-1.9+0.1\% CaPim & 21.5 & $43.9 \pm 1.4$ & $6.7 \pm 0.3$ & $591 \pm 5$ \\
\hline PP-4.2 & 6.6 & $72.7 \pm 1.7$ & $14.1 \pm 0.7$ & $682 \pm 6$ \\
\hline PP-4.2 + 0.1\% NA11 & 6.6 & $44.7 \pm 16$ & $12.7 \pm 0.6$ & $816 \pm 6$ \\
\hline PP-4.2+0.1\% CaPim & 6.8 & $69.8 \pm 1.2$ & $16.4 \pm 0.8$ & $594 \pm 2$ \\
\hline
\end{tabular}




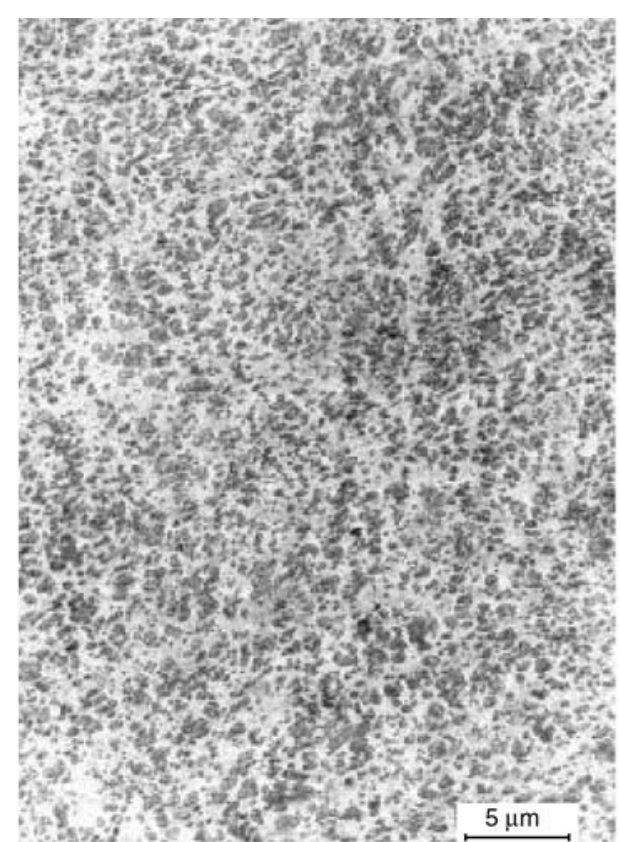

a)

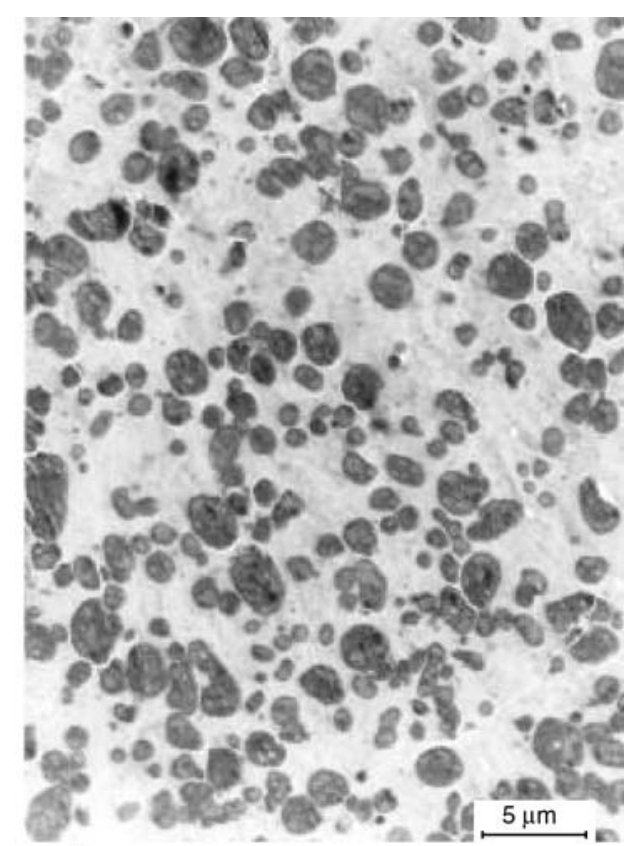

b)

Figure 2. $42.8 \times 31.4 \mu \mathrm{m}$ micrographs of PP-1.9 (a) and PP-4.2 (b). $\mathrm{RuO}_{4}$ stained thin cuts; transmission electron micrographs.

at refrigerator temperature for all the different nucleation configurations. The relativity of this interpretation will be show subsequently.

Indeed, the values obtained under standard conditions often do not reflect (and can thus not predict) the behaviour of a material over the entire relevant loading range. This feature was once more confirmed with our experiments. Figures 3 and 4 provide a deeper insight into the mechanical performance of the studied grades and demonstrate that differences between non-nucleated and nucleated grades are more pronounced for the blend with a low IV.

This conclusion is particularly true for the $\beta$-nucleated grades where at ductile-brittle transition shift of about $26^{\circ} \mathrm{C}$ towards lower temperature is observed with the PP-1.9 series between the neat grades and the $\beta$-nucleated resins. A synergistic combination of a small ligament length and intrinsic high ductility of the $\beta$-phase is here obvious. In fact, matrix shearing - which is believed to be the predominant damage form once the deformation initiated - is used to its full potential when the stress-fields of the particles are close enough and can overlap and is promoted by the intrinsic high mobility of the $\beta$-phase, a direct consequence of its specific microstructure in terms of lower packing density and favourable lamellar arrangement [25-27]. A confirmation of the crucial role of the

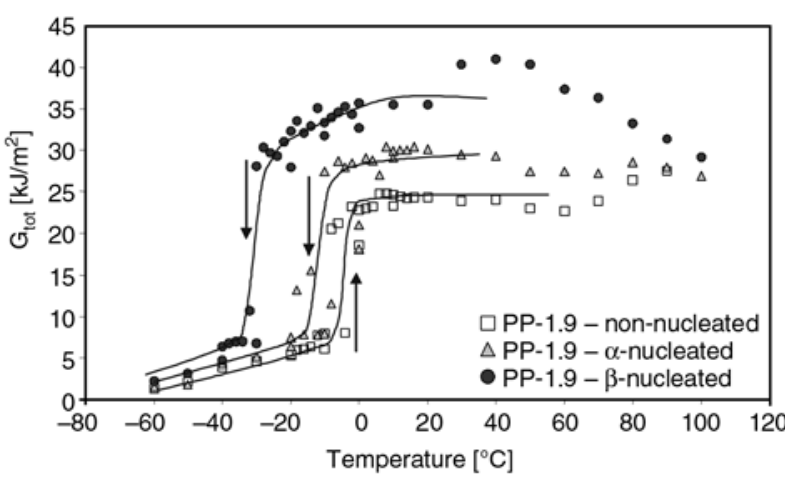

Figure 3. Work to break, $G_{t o t}$, plotted against temperature. Instrumented Charpy Pendulum. Test speed: $1.5 \mathrm{~m} / \mathrm{s}$. iPP/EPR blends with rubber IV of $1.9 \mathrm{dl} / \mathrm{g}$. The arrows represent the temperatures at which the ductile-brittle transitions occurred.

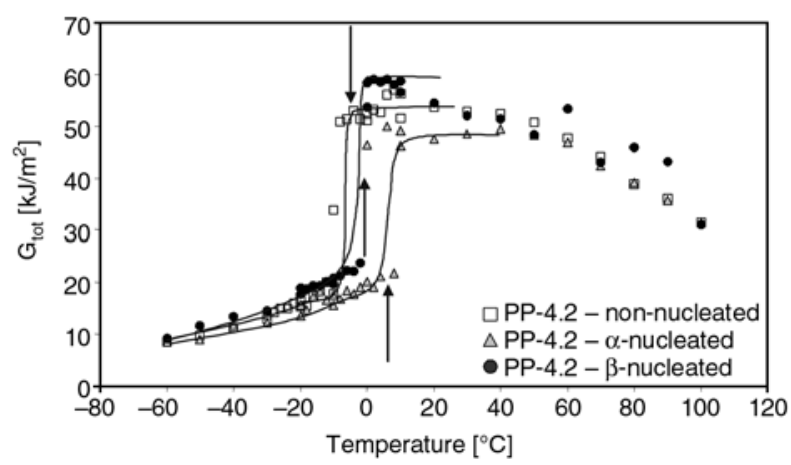

Figure 4. Work to break, $G_{t o t}$, plotted against temperature. Instrumented Charpy Pendulum. Test speed: $1.5 \mathrm{~m} / \mathrm{s}$. iPP/EPR blends with rubber IV of $4.2 \mathrm{dl} / \mathrm{g}$. The arrows represent the temperatures at which the ductile-brittle transitions occurred. 
distance between particles is provided by the $\beta$ modified PP-4.2 for which the fracture resistance behaviour is similar to the non-nucleated system. Here, the matrix ligament length is seemingly too wide to allow an effective stress transfer from the rubbery phase to the matrix and thus an effective use of the ductility of the $\beta$-phase.

Comparing the $\alpha$-nucleated grades among them is also instructive from a mechanistic point of view. For the low IV series, the non-nucleated material is outperformed by the $\alpha$-nucleated one. As no hint about an induced change of the particle size of both systems was given, such a result suggests that superstructure effects (like a smaller spherulitic size) dominate the $\alpha$-nucleation inherent embrittlement induced by a higher matrix crystallinity. Opposite conclusions are valid for the PP-4.2 grades.

Table 2 summarizes the temperatures at which the ductile-brittle occur for the different materials; the best combination is obtained with the $\beta$-nucleated PP-1.9 system - a fact which could hardly be foreseen with conventional notched impact strengths performed at given temperature and test speed (see Table 1). The relative performance of the grades within a nucleation group is representative for the interplay between the impact of the molecular weight of the rubbery phase and the resulting phase morphology.

Hence, for the non-nucleated systems no significant difference is observed between the ductile-brittle transitions of PP-1.9 and PP-4.2. Remembering that in an earlier study for iPP/EPR blends with $20 \mathrm{wt} \%$ of rubber the grade with the highest IV(XCS) outperformed by far its counterpart [28], one might conclude that the fracture behaviour of PP-4.2 is controlled primarily by the size of its particles while PP-1.9 is dominated by inter-particle factors. In other world, the initiation of the damage mecha-

Table 2. Temperature at which the ductile-brittle transitions occurred, $T_{d b}$, and work at fracture, $G_{t o t}$, at 23 and $-20^{\circ} \mathrm{C}$ for the investigated grades

\begin{tabular}{|l|c|c|c|}
\hline & $\begin{array}{c}\mathbf{T}_{\mathbf{d b}} \\
{\left[{ }^{\circ} \mathbf{C}\right]}\end{array}$ & $\begin{array}{c}\mathbf{G}_{\text {tot }}\left(\mathbf{2 3}^{\circ} \mathbf{C}\right) \\
{\left[\mathbf{k J} / \mathbf{m}^{2}\right]}\end{array}$ & $\begin{array}{c}\mathbf{G}_{\text {tot }}\left(\mathbf{- 2 0}{ }^{\circ} \mathbf{C}\right) \\
{\left[\mathbf{k J} / \mathbf{m}^{2}\right]}\end{array}$ \\
\hline PP-1.9 & -4 & 24.3 & 5.3 \\
\hline PP-1.9+0.1\% NA11 & -8 & 30.0 & 7.5 \\
\hline PP-1.9+0.1\% CaPim & -30 & 36.0 & 33.6 \\
\hline PP-4.2 & -6 & 53.5 & 16.5 \\
\hline PP-4.2+0.1\% NA11 & 0 & 48.0 & 15.7 \\
\hline PP-4.2+0.1\% CaPim & -4 & 53.0 & 19.0 \\
\hline
\end{tabular}

nisms (e.g. particle cavitation) is eased in PP-4.2 thanks to its bigger size while the propagation of the deformation forms (e.g. matrix shearing and crazing) is best for PP-1.9. Both contributions seem to counterbalance their respective influence leading to a $T_{d b}$ around $-5^{\circ} \mathrm{C}$ for both systems.

For the $\alpha$-nucleated systems, the inter-particle distance controls the fracture performance and it does - to an even larger extent - for the $\beta$-nucleated grades, with significantly lower ductile-brittle transition for the low IV series.

Such results have decisive implications in the polymer design of iPP/EPR blends:

- considering toughness as unique variable, it is extremely valuable to add $\beta$-nucleating agents to iPP/EPR blends with $32 \mathrm{w} \%$ rubber and low IV, since the ductile-brittle transition is shifted by almost $30^{\circ} \mathrm{C}$ towards lower temperature compared to a non-nucleated material;

- $\alpha$-nucleating agents can constitute a tool to improve both toughness and stiffness for grades with $32 \mathrm{wt} \%$ rubber and low IV. However, the differences between IV $=1.9$ and 4.2 (in terms of $T_{d b}$ ) are much less pronounced than with $\beta$-nucleation. Adjustment of rubber IV to design $\alpha$-nucleated iPP/EPR blends will therefore rather be governed by (i) the level of fracture resistance needed in both brittle and ductile ranges (compare $G_{t o t}$ at -30 and $+30^{\circ} \mathrm{C}$ for both grades) and (ii) total MFR required.

\section{Conclusions}

The influence of $\alpha$ - and $\beta$-nucleation on the toughness of two Impact PP copolymers (32 wt\% EPR) with different IV (1.9 and $4.2 \mathrm{dl} / \mathrm{g}$ ) was investigated. An assessment of ductile-brittle transitions over a wide temperature range rather than of punctual values as given by standard testing methods was used for this purpose.

The effect of nucleation was shown to be dependent on the inter-particle distance of the systems: While the fracture resistance was improved with low rubber IV in terms of ductile-brittle transition (i.e. shifts the $T_{d b}$ of the blend to lower temperatures), a negative to negligible influence for the grade with higher molecular weight (IV) was found.

$\alpha$-nucleation as well as $\beta$-nucleation therefore constitute powerful tools to optimise the toughness performance of iPP/EPR blends. Their selective use can be tailored for different applications. 


\section{References}

[1] Gahleitner M., Wolfschwenger J., Bachner C., Bernreitner K., Neissl W.: Crystallinity and mechanical properties of PP-homopolymers as influenced by molecular structure and nucleation. Journal of Applied Polymer Science, 61, 649-657 (1996).

[2] Pukánszky B., Mudra I., Staniek P.: Relation of crystalline structure and mechanical properties of nucleated polypropylene. Journal of Vinyl Additive Technology, 3, 53-58 (1997).

[3] Karger-Kocsis J., Mouzakis D. E., Ehrenstein G. W., Varga J.: Instrumented tensile and falling weight impact response of injection-molded $\alpha$ - and $\beta$-phase polypropylene homopolymers with various melt flow indices. Journal of Applied Polymer Science, 73, 1205-1214 (1999).

[4] Chen H. B., Karger-Kocsis J., Wu J. S., Varga J.: Fracture toughness of $\alpha$ - and $\beta$-phase polypropylene homopolymers and random- and block-copolymers. Polymer, 43, 6505-6514 (2002).

[5] Varga J., Ehrenstein G. W., Schlarb A. K.: Vibration welding of alpha and beta polypropylenes: Mechanical properties and structure. Express Polymer Letters, 2, 148-156 (2008).

[6] Kotek J., Scudla J., Slouf M., Raab M.: Combined effet of specific nucleation and rubber dispersion on morphology and mechanical behavior of isotactic polypropylene. Journal of Applied Polymer Science, 103, 3539-3546 (2007).

[7] Cao J., Zhao Z. Y., Du R. N., Zhang Q., Fu Q.: Effect of $\beta$ nucleating agent on mechanical properties of PP/POE blends. Plastics, Rubber and Composites, 36, 320-325 (2007).

[8] Bernreitner K., Hauer A., Gubo R.: Polyolefin composition with improved properties. EU patent, EP 1344793 (2003).

[9] Kasahara T., Kajiya T., Akiyoshi T.: Propylene-ethylene block copolymer composition. EU patent, EP 0137482 (1985).

[10] Schwager H., Hungenberg K-D.: Nucleated propylene polymers. EU patent EP 518121 (1992).

[11] Torgersen U., De Mink P., Bernreitner K.: Flat film for thermoforming. WO 2004055101 (2003).

[12] Bai H., Wang Y., Song B., Li Y., Liu L.: Effect of nucleating agent on the brittle-ductile transition behavior of polypropylene/ethylene-octene copolymer blends. Journal of Polymer Science, Part B: Polymer Physics, 46, 577-588 (2008).

[13] Grein C., Plummer C. J. G., Kausch H-H., Germain Y., Béguelin P.: Influence of $\beta$-nucleation on the mechanical properties of isotactic polypropylene and rubber modified polypropylene. Polymer, 43, 32793293 (2002).

[14] Varga J., Schulek-Tóth F.: Crystallization, melting and spherulitic structure of $\beta$-nucleated propylene random copolymers. Journal of Thermal Analysis and Calorimetry, 47, 941-955 (1996).
[15] Varga J.: $\beta$-modification of polypropylene and its twocomponents systems. Journal of Thermal Analysis and Calorimetry, 35, 1891-1912 (1989).

[16] Varga J., Garzó G.: The properties of polymer blends of the $\beta$-modification of polypropylene and an elastomer. Die Angewandte Macromoleculare Chemie, 180, 15-33 (1990).

[17] Zhang R., Zheng H., Lou X., Ma D.: Crystallization characteristics of polypropylene and low ethylen content polypropylene copolymer with and without nucleating agents. Journal of Applied Polymer Science, 51, 51-56 (1994).

[18] Fanegas N., Gómez M. A., Jiménez I., Marco C., Garcia-Martínez J. M., Ellis G.: Optimizing the balance between impact strength and stiffness in polypropylene/elastomer blends by incorporation of a nucleating agent. Polymer Engineering and Science, 48, 80-87 (2008).

[19] Menyhárd A., Varga J., Molnár G.: Comparison of different $\beta$-nucleators for isotactic polypropylene, characterisation by DSC and temperature-modulated DSC (TMDSC) measurements. Journal of Thermal Analysis and Calorimetry, 83, 625-630 (2006).

[20] Varga J.: $\beta$-modification of isotactic polypropylene: Preparation, structure, processing, properties and applications. Journal of Macromolecular Science, Part B: Phys, 41, 1121-1171 (2002).

[21] Turner Jones A,. Aizlewood A. M., Beckett D. R.: Crystalline forms of isotactic polypropylene. Die Makromolekulare Chemie, 75, 134-158 (1964).

[22] Pölt P., Ingolic E., Gahleitner M., Bernreitner K., Geymayer W.: Characterization of modified polypropylene by scanning electron microscopy. Journal of Applied Polymer Science, 78, 1152-1161 (2000).

[23] Labour T., Gauthier C., Séguéla R., Vigier G., Bomal Y., Orange G.: Influence of the crystalline phase on the mechanical properties of unfilled and $\mathrm{CaCO}_{3}-$ filled polypropylene, I. Structural and mechanical characterization. Polymer, 42, 7127-7135 (2001).

[24] Wu S.: A generalized criterion for rubber toughening: The critical matrix ligament thickness. Journal of Applied Polymer Science, 35, 549-561 (1988).

[25] Grein C.: Toughness of neat, rubber modified and filled $\beta$-nucleated polypropylene: From fundamentals to applications. Advances in Polymer Science, 188, 43-104 (2005).

[26] Varga J., Ehrenstein G. W.: High temperature hedritic crystallisation of $\beta$-modification isotactic polypropylene. Colloid Polymer Science, 275, 511-519 (1997).

[27] Trifonova-Van Haeringen D., Varga J., Ehrenstein G. W., Vancso G. J.: Features of the hedritic morphology of $\beta$-isotactic polypropylene studied by atomic force microscopy. Journal of Polymer Science, Part B: Polymer Physic, 38, 672-681 (2000).

[28] Grein C., Bernreitner K., Hauer A., Gahleitner M., Neiß1 W.: Impact modified isotatic polypropylene with controlled rubber intrinsic viscosities: Some new aspects about morphology and fracture. Journal of Applied Polymer Science, 87, 1702-1712 (2003). 